\title{
BOES 관측데이터의 자동처리 프로그램 개발 II DEVELOPMENT OF AN AUTOMATIC PROCESSING PROGRAM FOR BOES DATA II
}

\author{
강동일 ${ }^{1,2}$, 박홍서 ${ }^{1}$, 한인우 ${ }^{2}, \mathrm{G} . \mathrm{VALYAVIN}^{2}$, 이병철 ${ }^{2,3}$, 김강민 ${ }^{2}$ \\ ${ }^{1}$ 한국교원 대학교 \\ ${ }^{2}$ 천문연구원 \\ ${ }^{3}$ 경북대학교
}

Dong-II KAng ${ }^{1,2}$, Hong-Suh PARK ${ }^{1}$, In-WoO HAN ${ }^{2}$, G. VAlYAVIN ${ }^{2}$, BYEONG-CHEOL LEE ${ }^{2,3}$, AND KANG-MIN KIM ${ }^{2}$

${ }^{1}$ Korea National University of Education, Kang-Nae, Chung-Buk, 363-791, Korea

${ }^{2}$ Korea Astronomy Observatory, Daejeon 305-348, Korea

${ }^{3}$ Kyungpook National University, Daegu, 702-701, Korea

E-mail : dikang@boao.re.kr

(Received September 7, 2006; Accepted November 16, 2006)

\begin{abstract}
We developed a new program for automatic continuum normalization of Echelle spectrographic data. Using this algorithm, we have determined spectral continuum of almost BOES data. The first advantage of this algorithm is that we can save much time for continuum determination and normalization. The second advantage is that the result of this algorithm is very reliable for almost spectral type of spectrum. But this algorithm cannot be applied directly to the spectrum which has very strong and broad emission lines, for example Wolf-Rayet type spectrum.

We implanted this algorithm to the program which was developed in the previous study. And we introduced more upgraded BOES data reduction program. This program has more convenient graphical user interface environment, so users can easily reduce BOES data. Lastly, we presented the result of study on line profile variation of magnetic $\mathrm{Ap} / \mathrm{Bp}$ stars analyzed using this program.
\end{abstract}

key words: BOES - echelle spectrograph - automatic data reduction - continuum normalization

\section{1. 서론}

한국천문연구원에서는 보현산천문대 $1.8 \mathrm{~m}$ 망원경에 부착 된 고분산 에셀 분광기 $\mathrm{BOES}$ 의 관측 데이터를 자동 처리 하기 위한 프로그램 RX를 2005년에 개발하였다(강동일 외 2005). 이 프로그램은 관측으로 얻은 CCD 데이터를 전처리에서 시작하여 1 차원 스펙트럼 추출, 파장 동정 (wavelength calibration)을 마치고 파일로 저장하기까지의 모든 과정을 자동으로 처리한다. 이 논문은 그 후속 과정 으로서 연속선 정규화(continuum normalization)에 관한 연 구이다. 분광 관측을 이용한 천체물리 연구에서는 절대 광량 측정이 필요한 경우를 제외하고 대부분 연속선 정규 화를 필요로 한다. 시선속도 측정, 화학적 조성비 연구, 스펙트럼 변이 연구 등이 그 예이다. 따라서 연속선 정규 화는 분광 관측 데이터 처리에서 매우 중요한 부분이라고 할 수 있다. 분광 데이터 자동처리 프로그램은 많은 관측 데이터를 처리하는데 필요한 인력과 시간을 절감하고, 특
정 기기에 적합한 처리 기법을 적용하여 보다 정밀한 결 과를 얻을 수 있으며, 또한 데이터 처리 과정에서 연구자 의 자의적인 주관에 따른 오류를 방지하는 등의 장점이 있다.

분광 자료를 자동으로 처리하는 과정에서 가장 까다 로운 부분은 파장의 동정과 연속선 정규화라고 할 수 있 다. BOES는 광섬유를 통하여 빛이 입사되고 분광기는 안 정된 환경에서 운영되므로 시간에 따라 $\mathrm{CCD}$ 에 기록되는 스펙트럼의 파장별 위치가 거의 변하지 않기 때문에 파장 동정은 비교적 용이한 작업이다. 그러나 스펙트럼의 연속 선은 일정한 패턴이 없기 때문에 이것을 자동화하기 위해 서는 상당히 까다로운 기법이 요구된다. 이 논문은 파장 동정을 마친 분광 자료의 구경별 연속선을 결정하여 스펙 트럼을 정규화 하는 알고리즘을 소개한다. 그리고 $\mathrm{BOES}$ 자료의 자동처리 프로그램인 RX(강동일 외 2005)를 보다 사용하기 쉽게 향상시킨 GRX(graphical RX)를 소개하고 


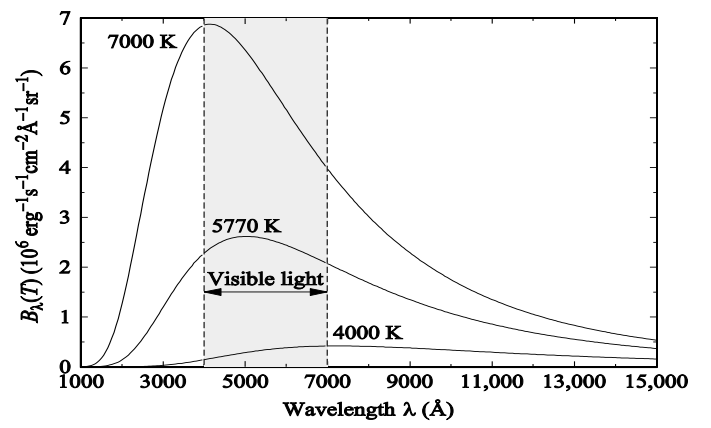

그림 1. 흑체복사에 의한 플랑크 곡선(Bradley \& Dale, 1996).

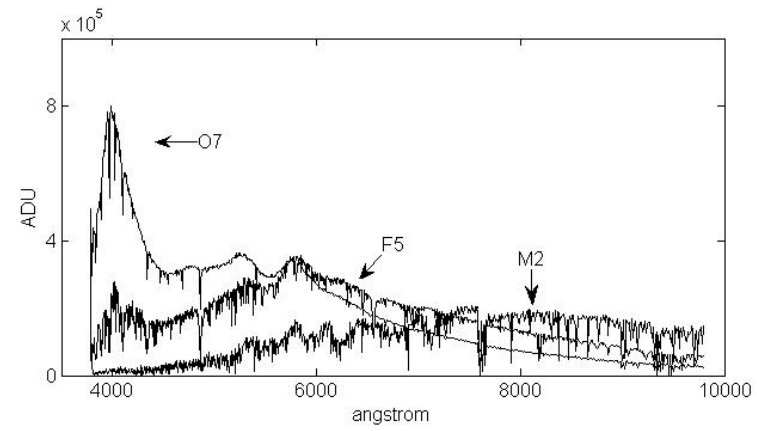

그림 2. BOES로 관측한 $\mathrm{O} 7, \mathrm{~F} 5, \mathrm{M} 2$ 형 스펙트럼.

사용자를 위한 프로그램의 운용 방법도 소개한다. 마지막 으로 GRX로 처리한 자기별(magnetic star)의 수소 스펙 트 럼 변화에 대한 분석 결과를 소개한다.

\section{2. 이론적 배경}

\section{1. 연속선과 연속선 정규화의 의미}

별은 흑체 복사를 하여서 그림 1 과 같이 플랑크 복사법칙 을 따르는 매끈한 연속 스펙트럼을 내어 놓을 것으로 가 정하지만 실제로는 이러한 연속 스펙트럼만이 관측되지 않는다. 우선, 천체 대기에서 많은 흡수선과 방출선이 만 들어지고, 성간 물질과 지구 대기에서의 차별적 흡수, 그 리고 분광기 특성에 의한 왜곡 등이 종합적으로 작용하기 때문이다. 그림 2는 $\mathrm{BOES}$ 로 관측한 스펙트럼 중에서 분 광형에 따른 몇 가지 예를 보여준다. 이 그림은 2 차원 분 광 이미지를 구경 방향으로 적분한 것으로 세로축의 단위 는 $\mathrm{ADU}(\mathrm{analog}$ to digital unit)이다. 그림에서 보듯이 분광 형별 스펙트럼 모습이 크게는 온도에 따른 플랑크 곡선을 반영하고 있으나 세부적으로는 전 파장에 걸쳐 매우 많은 흡수선이 겹쳐 나타나고 있다. 스펙트럼을 정규화 한다는 것은, 천체의 스펙트럼에서 흡수선이나 방출선에 의해 훼 손되기 이전의 연속선(continuum)을 추정하고, 스펙트럼을 이 연속선의 값으로 나누어서 연속선에 대한 비율로 스펙 (a)

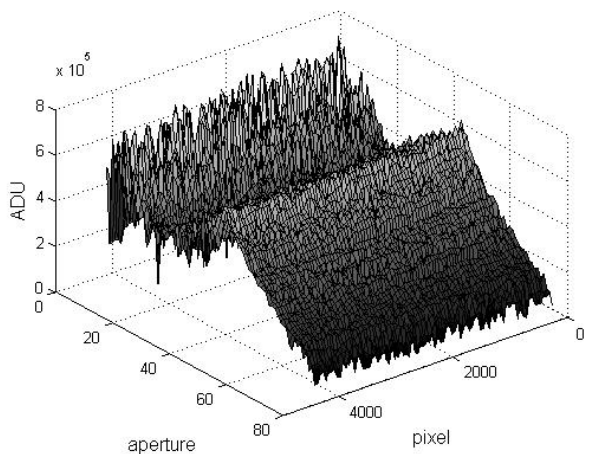

(b)

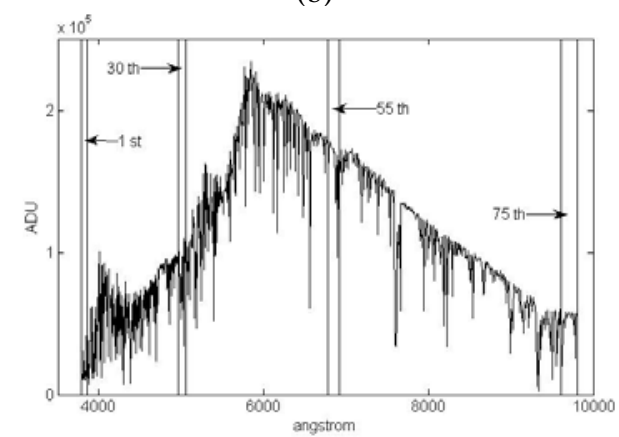

(c)

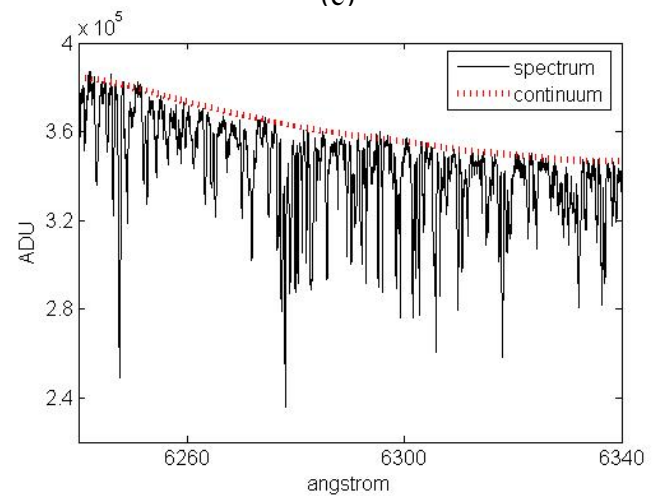

그림 3. HD 196502의 여러 가지 스펙트럼 모습. (a) 75개 의 구경 $\times 4102$ 화소로 되어 있는 2차원 스펙트럼, (b) 2 차원의 스펙트럼 이미지를 파장에 따라 연결한 모습, (c) 42 번째 구경의 스펙트럼만 확대한 모습

트럼을 나타내는 것을 의미한다. 따라서 정규화 에서는 관측한 스펙트럼에서 적절한 연속선을 찾는 것이 매우 중 요하다. 그런데 앞에서 보았듯이 흑체 복사 스펙트럼 모 습과는 매우 다르게 나타나는 실제 관측된 스펙트럼에서 연속선을 정밀하게 규정하는 것은 쉽지 않다. 대신 스펙 트럼 영역에서 연속선은 흡수선이나 방출선을 무시하고 그릴 수 있는 부드러운 곡선으로 되어 있을 것으로 쉽게 추정할 수 있다. 
그림 3(a)는 HD 196502를 연속선 정규화 이전 단계까지 처리한 모습이다. 한 구경당 화소수가 4102 개 이고 이러 한 구경이 75 개로 이루어져 있어, 자료는 전체적으로 $75 \times 4102$ 행렬로 구성되어 있다. 각 구경이 차지하는 파장 범위는 첫 번째 구경에서 좁고, 마지막 구경으로 갈수록 넓어지는데, 범위는 약 $3780 \AA$ 에서 $9800 \AA$ 까지이며 각 구 경의 가장자리에서는 파장이 조금씩 겹친다. 그림 3(b)는 여러 개의 구경으로 나뉘어 2차원으로 배열되어 있는 스 펙트럼을 파장을 따라 하나로 연결한 모습이다. 그림에서 보듯이 실제 관측 자료는 수많은 흡수선이 전 파장 영역 에 서로 다른 세기를 가지며 분포하고 있어 흑체복사에 의한 이상적인 플랑크 곡선과는 매우 다른 모습이다. 그 림 3(c)는 그림 3(a)에서 42번째 구경만 확대한 그림이다. 그림에서 실선은 실제 관측된 천체의 스펙트럼이고, 점선 은 이 천체에서 대기에 의한 흡수선이 없는 이상적인 경 우를 가정하고 표시한 연속선(continuum)이다. 이 경우에 는 큰 어려움 없이 연속선을 찾을 수 있다. 스펙트럼을 따라서 연속선이라고 생각되는 몇 점을 선택하고 이를 적 당한 차수의 다항식으로 맞추면 된다.

그러나 연속선을 결정하기가 매우 어려운 경우가 있 는데, 대표적으로 만기형의 차가운 별을 들 수 있다. 이 별들은 분자선을 비롯한 흡수선이 겹쳐 나타날 경우도 있 어 플랑크 곡선에 해당하는 부드러운 연속선을 찾기가 어 렵다. 그림 2의 M2 형 스펙트럼이 이에 해당한다. 다음으 로는 단일한 흡수선이 매우 넓은 경우로서, 그림 4와 같 은 $\mathrm{Ha}$ 선 영역을 들 수 있다. 에셀 분광기에서는 한 구 경이 차지하는 파장 영역이 좁기 때문에 이런 경우는 더 문제가 커진다. 때로는 $H a$ 영역이 한 구경을 벗어나는 경우도 있다. 이런 때는 정밀한 연속선 결정이 상당히 힘 들기 때문에 미세한 선 변화를 조사하는 연구에서는 연속 선 규정에 세심한 주의를 기울여야 한다.

\section{2. 프로그램 개발의 필요성}

이 논문은 앞에서 설명한 스펙트럼의 연속선을 자동으로 결정하는 프로그램의 개발에 대한 것이다. 이러한 프로그 램으로 기대할 수 있는 것은 우선 자료처리에 소요되던 시간을 줄일 수 있다는 것이다. 정확한 연속선 결정을 위 해서 대부분의 사람들은 수동으로 연속선을 결정하기를 선호한다. 이럴 경우 대량의 자료를 처리하는 데에 무시 할 수 없을 만큼의 시간이 소요된다. 향후 천문학의 변화 추세는 관측 프로그램의 대형화 등의 이유로 자료처리를 수동으로 하기에는 한계가 있어 자료 처리의 자동화가 대 세가 될 것이다.

자동화 프로그램으로 얻게 될 또 다른 장점은, 주어진
알고리즘 내에서 항상 일관적인 결과를 준다는 것이다. 수동으로 연속선을 결정하는 과정에서는, 사용자마다 다 른 결과를 얻을 수 있고, 같은 사용자라도 일관된 결과를 얻지 못하는 경우가 있다. 앞에서 예를 든 것같이, 처리가 힘든 스펙트럼의 경우 이런 문제점은 더 커진다.

\section{3. 연속선 정규화 알고리즘}

관측을 통해 우리는 바이어스, 플랫, 비교파장, 천체 프레 임 등 4 종류의 자료를 얻는다. 이 자료들은 마름질 (trimming), 플랫 및 바이어스 프레임 합치기, 바이어스 보 정, 1 차원 추출, 배경값 제거, 바닥 고르기 등의 전처리를 한다. 이후 비교파장 프레임을 이용하여 스펙트럼의 구경 별 파장 관계를 결정하면 연속선 정규화 이전의 자료 처 리 과정이 끝난다. 이 단계 이후의 스펙트럼 정규화 알고 리즘에 대하여 구체적으로 설명하기로 한다.

연속선 정규화에서는 가장 적절한 연속선을 결정하는 것이 관건이다. 일반적으로 IRAF나 MIDAS를 이용하여 자료처리 할 때는, 연속선은 스펙트럼에서 흡수선이나 방 출선이 없는 부분을 시각적으로 확인하고 이러한 몇 개의 점을 적절한 함수로 맞추어서(function fitting) 연속선을 결 정한다. 이 경우에는 다양한 분광형의 자료가 주어지더라 도 적절한 연속선을 찾을 수 있지만 사용자의 주관이 개 입되어 저마다 다른 결과를 얻을 수가 있고, 상당히 많은 시간이 소요되는 단점이 있다.

Eduardo(1996)은 분광형에 따라 흡수선이나 방출선이 없는 파장의 정보를 미리 기억하고 있다가 해당 파장에서 의 값들로 함수 맞추기 하여 연속선을 결정하는 방법을 제시하였다. 이러한 방법은 사전에 분광형 별로 연속선의 정보가 필요하고, 스펙트럼에 어떤 변화가 있을 경우에 적절히 대처할 수 없다는 단점이 있다.

LaSala와 Kurtz(1984)는 연속선이 보이는 매우 부드러 운 변화의 패턴과 흡수선이 보이는 작은 변화들이 중첩되 어 스펙트럼을 형성한다는 성질을 이용하였다. 이 방법은 스펙트럼을 푸리에 변환한 후, 고주파수 성분을 체계적으 로 제거하여 저주파수 성분만 남기면 이것이 바로 연속선 이 보이는 패턴에 의한 주파수 성분이라고 가정하였다. 따라서 이것을 다시 역변환하면 연속선만 남은 스펙트럼 을 얻을 수 있다는 것이다. 이것은 Luo와 Zhao(2001)가 이 용한 웨이블릿 변환을 통한 연속선 결정법과 같은 원리이 다. 이러한 방법은 신호에서 잡음을 제거하는 일반적인 방법이지만 천체의 스펙트럼에서 연속선에 대해서 흡수선 과 방출선이 보이는 세기와 분포의 패턴은 본질적으로 신 호에 대해 잡음이 갖고 있는 패턴과는 다르다. 천체의 스 펙트럼은 물리적 상황에 따라 매우 다양하고 수소의 발머 
선과 같은 경우에는 한 구경에서의 연속선보다 더 넓은 파장에 걸쳐 있기도 하기 때문이다.

본 연구에서는 기존의 연속선 결정방법이 갖는 취약 점을 모두 극복하고 어떠한 분광형의 자료에도 적용 할 수 있는 연속선 결정 알고리즘을 개발하고자 하였다. 알 고리즘은 다음 두 가지 조건을 만족시키는 방향으로 개발 하였다. 첫째, 사람의 눈으로 연속선을 결정하듯이 스펙트 럼 그 자체로부터 연속선을 결정하도록 하였다. 스펙트럼 의 주기 분석이나 연속선이 있는 파장의 정보를 가져와서 간접적으로 연속선을 결정하는 방법은 다양한 패턴을 보 이는 스펙트럼에 대해 유연하게 대처하지 못하기 때문이 다. 둘째, 흡수선이 너무 강해 연속선의 정보가 거의 없는 스펙트럼에서의 어려움을 해결 하고자 하였다. 이것은 대 부분의 기존 알고리즘이 갖고 있던 문제인데, 연속선 결 정을 자동화하기 위해서는 반드시 이 부분을 구현할 수 있어야 하였다.

위 두 조건을 만족하는 연속선 결정 알고리즘을 개발 하기 위해 2차원으로 배열되어 있는 스펙트럼이 가지는 다음 두 성질을 이용하였다.

성질 1. 각 구경에서의 스펙트럼은 흑체복사에 의한 플 랑크 함수의 일부분이다.

그림 3(b)에서 보듯이 천체의 스펙트럼은 이론적으로 플 랑크 함수의 형태를 보이고, 각 구경은 전체 플랑크 함수 의 일부일 뿐이다. 따라서 각 구경에서의 스펙트럼은 플 랑크 곡선의 한 조각으로 다룰 수 있다. 이럴 경우, 한 구 경의 연속선은 아주 부드러운 곡선의 모습을 가질 것이 다.

성질 2. 연속선은 구경방향으로도 연속성이 있다. 각 구경은 서로 다른 파장 범위에 있지만 인접한 구경끼 리는 전체 플랑크 함수에서 비슷한 파장 간격으로 배열되 어 있다. 따라서 2 차원 분광 이미지에서는 연속선이 파장 방향뿐만 아니라 구경 방향으로도 부드럽게 변화한다(그 림 3(a)).

본 연구에서는 연속선이 갖는 위 두 가지 성질을 이 용하여 이상적인 연속선을 결정하는 알고리즘을 개발하였 다. 이 알고리즘에서 자료를 처리하는 과정을 순서대로 소개한다.

\section{1. 중간값 필터링(median filtering)}

이 단계는 매우 강한 흡수선에 의해 연속선 정보가 거의 훼손되어 해당 구경의 스펙트럼만으로는 연속선 결정이
어려운 구경의 연속선 정보를 되살려서 다음 단계에서 연 속선 결정 연산이 수행될 수 있도록 하는 준비 과정이다.

그림 4(a)는 강한 $H_{\mathrm{a}}$ 흡수선을 보이는 52번째 구경과 그 전후 구경의 스펙트럼을 함께 나타낸 것이다. 그림에 서 보듯이 52번째 구경에는 전 스펙트럼 영역에 걸쳐 $H_{\mathrm{a}}$ 선이 나타나므로 연속선의 정보가 거의 없다. 반면 인접한 구경 $(51,53$ 번째 구경)에서는 약한 흡수선 사이에 연속선의 정보가 남아 있다. 성질 2에 의하면 인접한 구 경은 연속선 사이에도 연속성(continuity)이 있으므로 연속 선이 거의 없는 구경의 연속선 정보는 주변 구경의 연속 선에서 가져올 수 있다. 이를 위해 2차원 스펙트럼 배열 을 구경 방향으로 중간값 필터링 연산을 하였다. $m$ 번째 구경에 있는 화소 $x$ 의 값을 $I(m, x)$ 라 두면 중간값 필 터링한 값 $M(m, x)$ 은 다음과 같이 구해진다.

$$
\begin{array}{r}
M(m, x)=\operatorname{med}[I(m-n, x), I(m-(n-1), x) \\
, \ldots, I(m+(n-1), x), I(m+n, x)]
\end{array}
$$

위 공식에서 med 함수는 중간값을 취하는 함수이고, $\mathrm{n}$ 은 필터의 크기이다. 필터의 크기를 다양한 값으로 시험 해 본 결과 $n=2$ 가 적당하였다. 이것은 $n=1$ 로 두었을 경우 인접한 구경에서도 강한 흡수선이 있으면 흡수선들 끼리 중간값이 취해질 수가 있고, $\mathrm{n}>2$ 로 너무 큰 경우 에는 중간값이 어느 한 쪽으로 치우쳐서 실제 연속선보다 낮거나 높아질 수 있기 때문이다.

이 연산으로 강한 흡수선에 의해 연속선이 훼손된 부 분은 인접 스펙트럼과의 중간값으로 대체되어 부분적으로 연속선이 회복된다(그림 4(b)). 이 결과 모든 구경은 연속 선의 정보를 가지고 있으므로 이를 이용하여 연속선을 결 정할 수 있게 된다. 다음 절에서 실제 연속선을 결정하는 과정을 설명한다.

\section{2. 반복적 상향 평활법(IUS : Iterative Uplift-Smoothing method)}

2차원 스펙트럼 배열이 갖는 성질 1 에 의하면 어느 한 구 경은 플랑크 곡선의 일부로서 BOES의 경우에는 30 100 ̊ 에 해당하는 좁은 영역이다. 이렇게 좁은 파장 영역에서 연속선은 거의 직선이나 매우 부드러운 곡선으로 근사할 수 있을 것이다. 동시에 그 곡선의 값은 연속선의 수준으 로 올려져야 된다. 연속선 결정 알고리즘은 연속선이 다 음의 두 가지 조건을 만족하도록 고안되었다.

조건 1. 연속선은 직선에 가까운 부드러운 곡선이다.

조건 2. 이 곡선 전체가 연속선 수준의 값을 가져야 한다. 
(a)

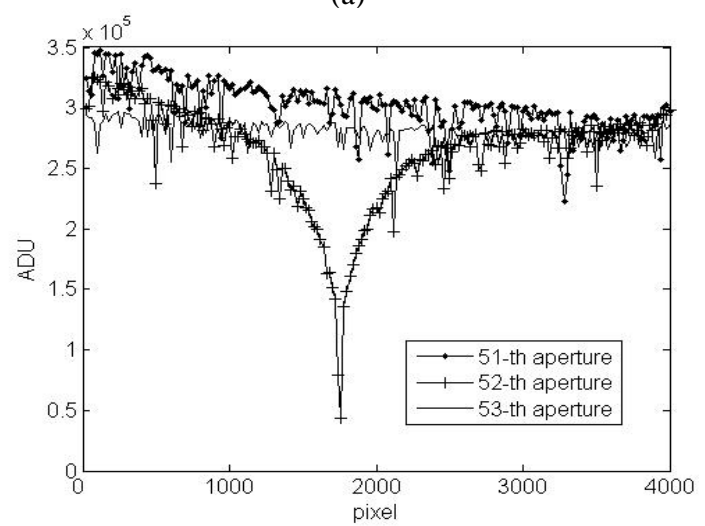

(b)

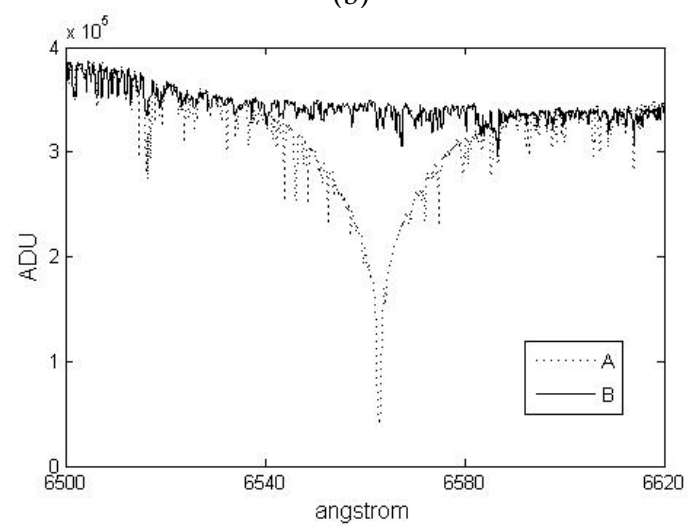

그림 4. BOES로 획득한 $\mathrm{HD} 196502$ 의 $\mathrm{Ha}$ 를 포함한 52 번째 구경의 스펙트럼에 대한 중간값 필터링 과 정을 보여주는 그림. (a) 중간값 필터링 하기 이전 주변 구경 스펙트럼과 함께 나타낸 모습, (b) 52번 째 구경을 포함한 주변 5 개 구경에서의 중간값으로 구한 새로운 스펙트럼(선 B)과 원래의 스펙트럼(선

A)

첫 번째 조건을 만족하도록 하기 위해서 스펙트럼을 평활 (smoothing) 하는 방법을 이용하였고, 두 번째 조건을 만족 하도록 하기 위해서 평활된 스펙트럼을 원래 스펙트럼에서 흡수선 사이에 남아 있는 연속선 수준의 값으로 조금씩 들 어 올린다. 이러한 과정을 적절히 반복하면 위 두 조건을 만족하는 연속선을 얻게 된다. 그런 의미에서 이 알고리즘 을 반복적 상향 평활법, 줄여서 IUS 라고 하자. 다음에서 IUS가 자료를 다루는 과정을 순서대로 소개한다.
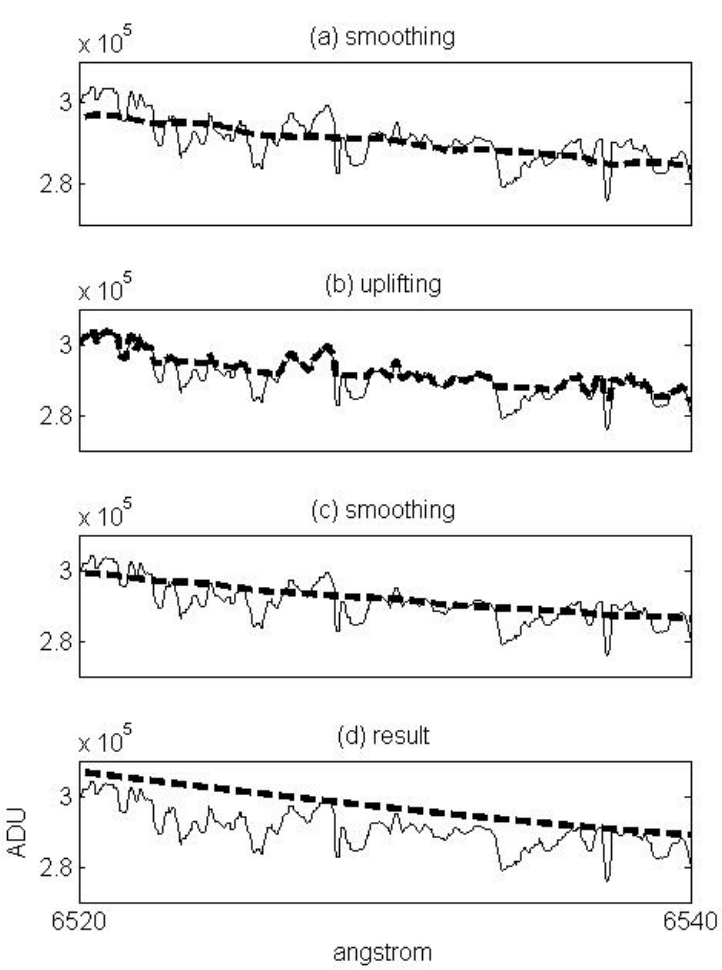

그림 5. IUS가 스펙트럼의 연속선을 결정하는 과정을 순 서대로 나타낸 모습

(1) 평활(smoothing)

평활은 말 그대로 부드럽게 편다는 뜻으로서 흡수선으 로 인해 거칠어진 스펙트럼으로부터 위 조건 1을 만족하 는 부드러운 연속선의 모양을 찾을 수 있게 하는 기법이 다.

평활은 선형 평활, 가우시안 평활, 사비츠키-골레이 평 활, 로버스트 평활 등 매우 다양한 기법들이 있다 (William 2002). 이 방법들을 모두 시험하여 본 결과 비교 적 구현하기에 간단하고 연산속도가 빠르며 연속선을 잘 결정해 주는 선형 평활을 평활기법으로 채택하였다.

선형평활은 이동평균(moving average)과 같은 연산이 다. $m$ 번째 구경의 어느 화소 $x$ 에서의 값을 $I(m, x)$ 라 했을 때, 이동평균 된 값 $S(m, x)$ 는 다음과 같이 구한 다.

$$
S(m, x)=\frac{1}{2 n+1} \sum_{i=-n}^{n} I(m, x+i)
$$




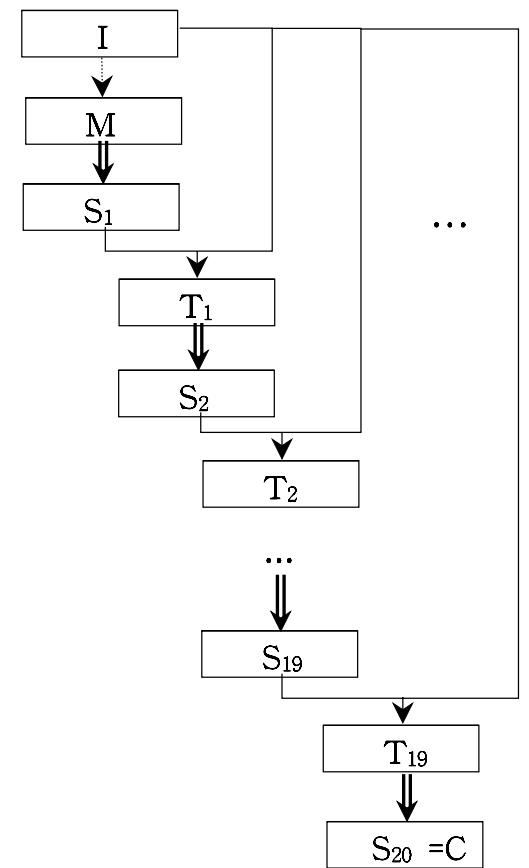

그림 6. IUS의 연산과정 모식도. 네모 칸 안의 $\mathrm{I}$ 는 천체 스펙트럼, $\mathrm{M}$ 은 중간값 필터링으로 구한 스펙트럼, $\mathrm{S}$ 는 평활로 구한 스펙트럼, $\mathrm{T}$ 는 $\mathrm{S}$ 와 I를 비교하여 큰 값만 을 취한 스펙트럼을 의미한다. $\mathrm{S}$ 와 $\mathrm{T}$ 에서의 첨자는 연 산 횟수를 의미한다. 화살표는 연산에 의한 자료의 이 동으로 $\rightarrow \rightarrow$ 는 중간값 필터링, $\Rightarrow$ 는 평활, $\rightarrow$ 는 식 (3)에 의한 연산을 의미한다.

이동평균은 평균을 취하는 범위에 따라 결과가 달라지므 로 이것을 적절히 정하는 것이 매우 중요하다. 범위가 너 무 작을 경우 강한 흡수선과 방출선의 영향으로 $S(m, x)$ 가 조건 1 을 만족하기 어렵고, 너무 넓을 경우에 는 연속선을 지나치게 선형화 해 버리는 결과를 가져온 다. 조건 1 을 만족하려면 범위는 연속선이 적절한 선형성 (linearity)을 갖도록 경험적으로 결정하는 것이 타당하다. 다양한 자료에 대해 시험 해 본 결과, 스펙트럼 전체 화 소인 4102 화소의 약 $1 / 8$ 에 해당하는 500 화소 정도로 했 을 때, 가장 적절한 연속선을 얻을 수 있었다(그림 5(a)). 위 공식 (2)에서는 $\mathrm{n}=250$ 이 되어 이동평균의 구간범위 는 총 501화소가 된다.

(2) 연속선 수준으로 들어올리기

스펙트럼을 평활하면 조건 1을 만족하는 부드러운 연속선 의 모양을 얻을 수 있지만 흡수선과 함께 평균되었으므로 이 결과는 연속선 수준의 값을 가지지 못한다. 그래서 평 활로 얻은 곡선은 조건 2 를 만족하도록 올려져야 한다.
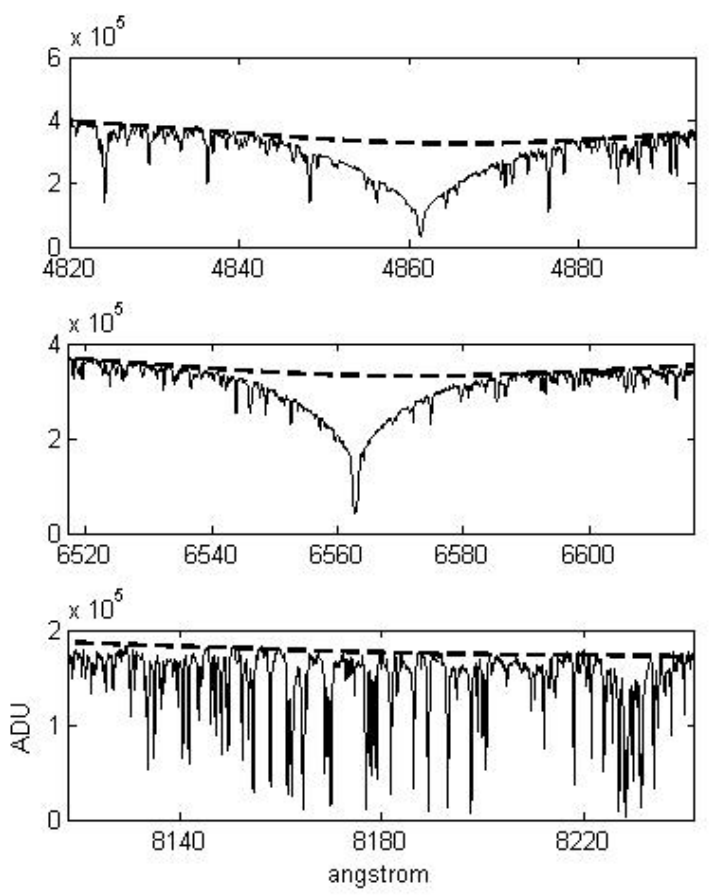

그림 7. IUS를 통해 HD196502의 여러 구경에서 연속선 (점선)이 결정된 모습. 가장 위는 $H_{\beta}$ 선을 포함한 22 번 째 구경, 가운데는 $H_{\mathrm{a}}$ 를 포함한 52번째 구경, 그리고 맨 아래는 지구 대기에 의한 흡수선이 많은 66번째 구 경의 스펙트럼이다.

이를 위해 스펙트럼 $I(m, x)$ 와 이를 중간값 필터링한 후 평활 하여 얻은 스펙트럼 $S(m, x)$ 를 모든 화소에서 비 교하여 높은 값만을 취한 새로운 스펙트럼 $T(m, x)$ 을 만든다(그림 5(b)).

$$
T(m, x)=\left\{\begin{array}{l}
I(m, x), \text { if } I(m, x)>S(m, x) \\
S(m, x), \text { if } S(m, x)>I(m, x)
\end{array}\right.
$$

(3) 반복하기

단계 (2)에서 $T(m, x)$ 를 연산하는 과정에서 $I(m, x)$ 의 복잡한 흡수선 모양 일부가 다시 나타나게 된다(그림 5(b)). 그래서 $T(m, x)$ 을 다시 단계 (1)에 투입하여 평활 하면 처음 평활했던 것보다 조금 더 높아진 곡선을 얻게 되고 이것을 또 단계 (2)를 통해서 연속선 수준으로 조금 더 들어 올린다. 이러한 상향 평활을 충분히 반복하여 그 림 5(c)와 같은 중간 단계의 $S(m, x)$ 를 거쳐서 우리가 충분히 이 스펙트럼에서의 연속선 이라 생각할 수 


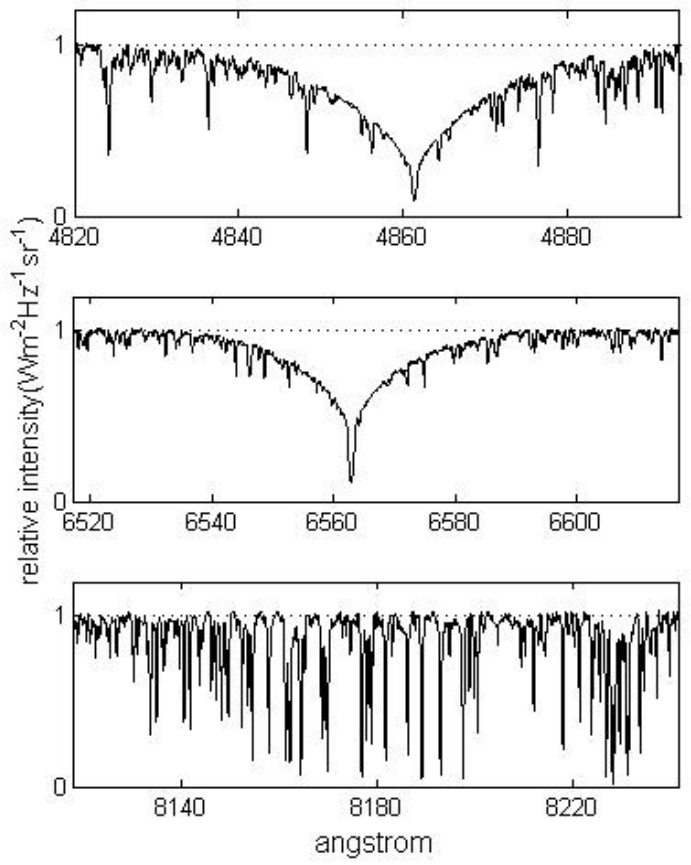

그림 8. 그림 7의 각 스펙트럼을 연속선에 대해 정규화 한 모습

있는 수준이 되면(그림 5(d)) 반복 연산을 종료하고 이 때 의 $S(m, x)$ 을 연속선 $C(m, x)$ 로 결정한다. 그림 6 에 IUS의 연산과정을 순서도로 나타내었다.

그림 7은 파장이 다른 세 구경의 스펙트럼(가는 실선) 과 이 스펙트럼에서 IUS로 얻은 연속선(굵은 점선)을 나 타낸 것이다. 그림에서 보듯이 이 알고리즘으로 구한 연 속선은 다양한 파장영역의 스펙트럼에서 연속선을 잘 반 영해 주고 있다.

다음으로 넘어가기 전에, IUS의 반복 연산 횟수에 대 한 고찰이 필요하다. 반복 연산 횟수가 너무 작은 경우에 는 그림 5(c)와 같은 상황에서 연산이 종료되므로 실제 연 속선보다는 너무 낮은 연속선을 얻게 된다. 반대로 반복 연산 횟수가 너무 큰 경우를 생각해 보자. 그림 5(d)와 같 이 이미 결정된 연속선은 식 (2), (3)의 추가 연산을 더 시 행해도 값의 변화가 거의 없다. 따라서 반복 연산 횟수가 너무 크면 부가적인 연산을 하게 되는 셈이다. 스펙트럼 에 따른 IUS의 적절한 반복횟수는 그 스펙트럼에 있는 흡 수선의 세기에 따라 달라질 것이다. 흡수선이 많고 세기 가 강한 만기형 별의 스펙트럼 $I_{\text {late }}(m, x)$ 과 이것을 이동 평균한 $S_{\text {late }}(m, x)$, 그리고 흡수선이 적고 세기가 약한 조 기형 별의 스펙트럼 $I_{\text {early }}(m, x)$ 과 이것을 이동

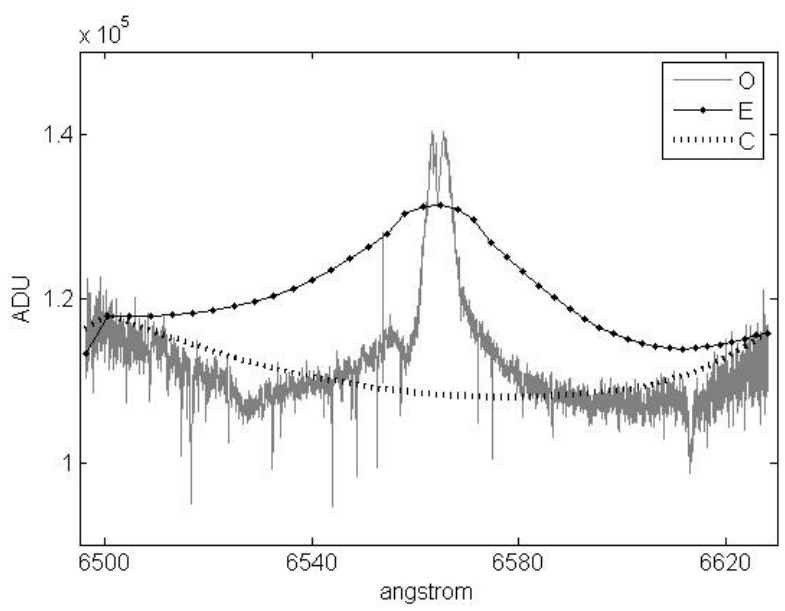

그림 9. $\mathrm{Ha}$ 의 강한 방출선을 보여주는 HD30614의 52번 째 구경. 방출선의 경계 $x_{1}, x_{2}$ 는 스펙트럼에서 눈으 로 확인하여 결정하였다.

평균한 $S_{\text {early }}(m, x)$ 를 생각해 보자. $S_{\text {late }}(m, x)$ 은 흡 수선의 영향으로 $S_{e a r l y}(m, x)$ 보다 연속선에 대해 더 낮은 값을 가질 것이므로 연속선에 수렴하기까지 보다 더 많은 반복 연산을 필요로 한다. 모든 분광형에 대해서 IUS로 연속선을 결정하여 보니 만기형 별에서 IUS의 적 절한 반복횟수는 20 회 였고, 조기형에서는 15 18회 정도 로도 충분했다.

IUS의 반복 연산 횟수에 대해서는 보다 많은 자료로 통계적 확인을 해 볼 필요가 있다. 본 연구에서는 모든 분광형에 대해서 IUS의 반복 횟수를 20 회로 고정하였다. 이럴 경우 조기형 별의 스펙트럼에서는 초과 연산을 하게 되는데, 이것은 앞에서 언급한대로 이미 연속선이 결정되 면 초과 연산을 하더라도 연속선에는 거의 변화가 없어서 자료 처리 시 천체의 분광형을 특별히 고려하지 않아도 되기 때문이다.

\section{3. 스펙트럼의 정규화}

연속선을 결정했다면 연속선으로 정규화 된 스펙트럼 $N(m, x)$ 은 천체의 스펙트럼 $I(m, x)$ 을 연속선 $C(m, x)$ 으로 나누어서 구할 수 있다.

$$
N(m, x)=\frac{I(m, x)}{C(m, x)}
$$

그림 8은 그림 7의 각 스펙트럼을 정규화 한 결과이다. 스펙트럼을 정규화 하였으므로 세로축은 각 파장별 에너 
지의 상대세기(relative intensity)이다. 천체의 스펙트럼이 연속선에 대한 비율로 나타나 있음을 확인할 수 있다.

\section{4. 문제점}

천체는 고유의 연속선이 있고 이것이 대기에서 흡수되어 흡수선을 형성한다. 따라서 일반적인 천체의 스펙트럼은 연속선에 흡수선이 중첩되어 나타나는 것이다. IUS는 흡 수선에 의해 세기가 약해진 스펙트럼을 연속선의 수준으 로 끌어 올려 전체적인 연속선을 결정하는 알고리즘을 사 용하므로 스펙트럼에 미약한 방출선이 있을 경우 이것에 의해 연속선이 조금 높게 결정될 수가 있다. 하지만 이러 한 방출선은 흡수선에 비해 매우 미약해서 IUS에서의 평 활과정에서 약한 방출선에 의한 오차는 거의 없어진다.

하지만 매우 강하고 폭넓은 방출선을 포함한 스펙트럼의 경우에는 IUS를 그대로 적용할 수 없다. 그림 9는 $\mathrm{Ha}$ 의 강한 방출선을 포함하고 있는 $\mathrm{O}$ 형 초거성 a Cam의 스펙 트럼이다. 이 방출선은 a Cam로부터 분출되는 항성풍에 의한 것으로(Markova, 2002) 매우 넓은 파장에 걸쳐 있다. 이러한 구경에 IUS를 이용할 경우에는 이 방출선의 영향 으로 $\mathrm{E}$ 와 같이 부적절한 연속선을 결정하게 된다. 이를 방지하기 위해서는 미리 스펙트럼을 관찰하여 이러한 영 향을 미칠만한 방출선을 확인한 후, 방출선 범위 내의 값 들을 방출선 좌우 경계 $x_{1}, x_{2}$ 에서의 값 $I\left(m, x_{1}\right), I\left(m, x_{2}\right)$ 으로 선형 내삽한 $I^{\prime}\left(m, x_{1}\right)$ 으로 대체해 놓고 연속선을 결정하도록 하였다.

$$
I(m, x)=I\left(m, x_{1}\right)+\frac{x-x_{1}}{x_{1}-x_{2}}\left(I\left(m, x_{1}\right)-I\left(m, x_{2}\right)\right)
$$

이렇게 만들어진 임시 스펙트럼에 대해 IUS를 적용하면 강한 방출선에 의한 효과를 배제한 연속선 C를 결정할 수 있다.

\section{GUI 환경의 GRX 사용법}

$\mathrm{RX}$ 는 최초에 GUI(graphical user interface) 환경으로 개발 되지 않았다. 따라서 사용자가 자료 처리의 진행과정을 알 수가 없고, 문제 발생 시 어느 부분에 문제가 있는지 확인하기가 어려운 점이 있었다. 그래서 자료 처리의 과 정을 사용자에게 시각적으로 보여주고, 사용하기에 익숙 한 환경으로 만들기 위해그래픽 환경으로 구성된 GRX(graphical RX)를 만들었다. GRX는 이 프로그램의 개 발 언어인 MatLab의 GUIDE(graphical user interface development environment)를 이용하여 개발하였다.

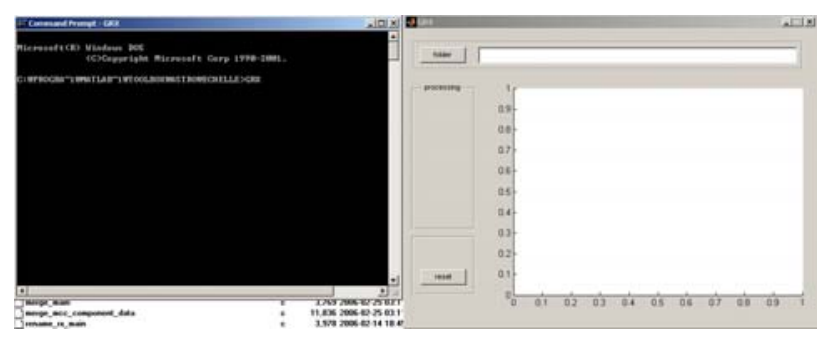

그림 10. GRX.exe를 실행했을 때 프로그램이 시작된 모 습. 왼쪽은 프로그램의 진행상황에 대한 설명이 나오는 콘솔(console)이고 오른쪽은 프로그램의 GUI 이다.

$\mathrm{GRX}$ 가 사용하는 모든 함수는 이전 프로그램인 RX의 함 수를 그대로 사용하였다. 프로그램 GRX의 설치와 사용법 을 다음에 소개한다.

\section{1. 프로그램의 설치}

프로그램및 이와 관련한 모든 파일들은 BOES 홈페이지 (http://www.boao.re.kr/BOES/RX.html)에 접속해서 누구나 다운로드 하여 사용할 수 있도록 하였다. BOES 홈페이지 에서 제공하는 파일은 소스코드와 컴파일 된 파일까지 모 두 포함하므로 MatLab 사용자는 소스코드를 이용하

거나 컴파일 된 GRX.exe를 실행시키면 곧바로 GRX를 이 용할 수 있다. 하지만 MatLab이 설치되지 않은 컴퓨터에 서는 MatLab용 구동 엔진(MCRInstaller.exe)을 먼저 설치하 고 난 후 GRX.exe를 실행하여야 한다. 함께 제공하는 파 일 중에 확장자가 .mat 인 파일은 GRX.exe와 같은 폴더 내에 있어야 하는 것에 유의 하여야 한다.

\section{2. 프로그램 사용법}

$\mathrm{GRX}$ 를 이용하여 자료처리를 수행하는 과정을 순서대로 소개한다.

(1) 자료 준비

GRX로 처리할 관측 자료는 모두 같은 폴더 내에 저장되 어 준비되어야 한다. 천체 프레임, 바이어스, 플랫, ARC 프레임 중 어느 하나라도 없거나 이상이 있으면 해당 프 레임을 처리하는 과정에서 프로그램은 경고 메시지를 내 고 멈춘다.

(2) 프로그램 실행 및 폴더 설정

GRX.exe를 실행하면 자료 처리 과정의 설명이 나올 도스 터미널과 자료처리를 수행할 패널이 함께 뜬다. 패널의 ${ }^{『}$ folder』 버튼을 눌러서 자료가 저장된 폴더를 지정 


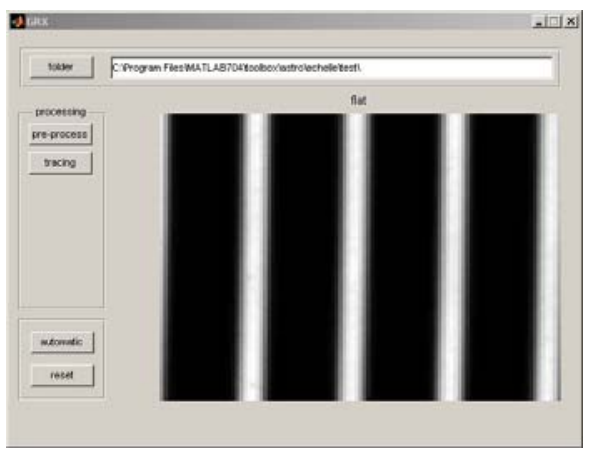

그림 11. 플랫 프레임 합치기를 마친 후 GRX가 마스터 플랫을 사용자에게 보여주는 모습

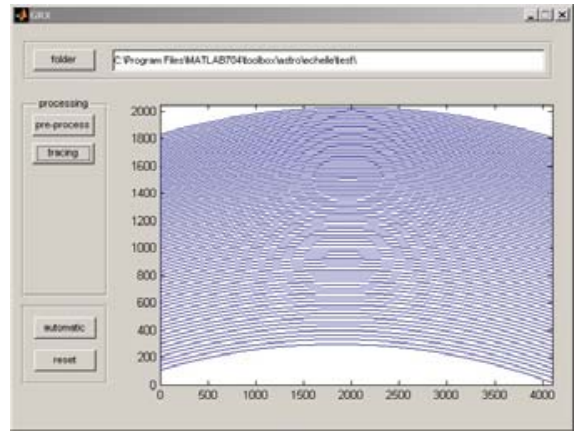

그림 12. 구경의 위치를 확인한 후 사용자에게 보여주는 모습. 구경은 아래에서 위로 증가한다.

하면 프로그램은 해당 폴더 내에서 확장자가 fits 인 모든 파일의 헤더를 읽어서 메모리에 저장하고 파일의 리스트 를 도스 터미널에 보여준다. 그런 다음 단계인 『pre-processing』 단추가 숨어 있다가 활성화 되면서 사용 자에게 다음 단계를 알려 준다.

(3) 전처리 : 『pre-processing』

폴더 내의 자료를 확인하고 이상이 없으면 전처리 단계로 넘어간다. 패널에 활성화 되어 나타난 『pre-processing』 단추를 누르면 프로그램은 이미 기억하고 있던 파일의 정 보를 이용하여 전처리 과정을 수행한다. 프로그램은 전처 리의 세부 단계가 끝날 때마다 결과를 터미널과 패널의 그 래프에 보여준다. 그림 11은 플랫합치기(flat combining)로 얻은 마스터 플랫의 일부를 보여주는 화면이다. 사용자는 이 그림을 통해서 전처리 과정의 이상 여부를 확인할 수 있다.

(4) 구경 위치 확인 : 『tracing』

전처리가 끝나면 『tracing』단추가 활성화 되고, 이 단추 를 누르면 전처리를 통해 얻은 마스터 플랫을 이용하여

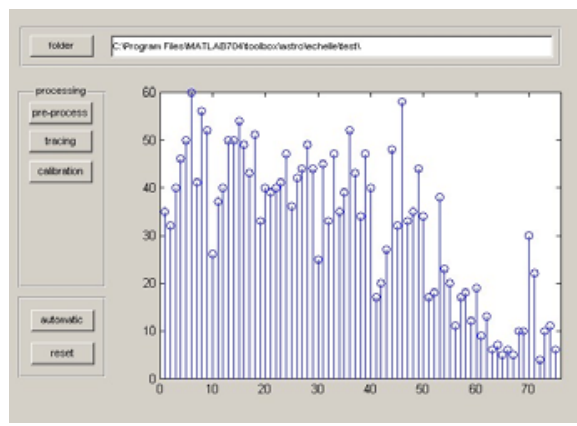

그림 13. ARC 프레임의 파장을 동정한 후 각 구경에서 찾은 방출선의 개수를 보여주는 모습. 가로축은 구경이 고 세로축은 각 구경에서 찾은 방출선의 개수이다.

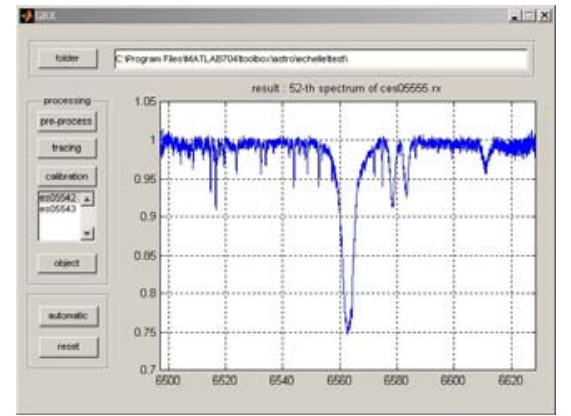

그림 14. 천체 프레임의 모든 자료처리를 마친 후 사용자 에게 $H_{a}$ 선을 포함한 구경의 스펙트럼을 보여 주는 모습. BOES의 75 개 구경 중에서 52번째 구경이 $H_{\mathrm{a}}$ 를 포함한 구경이다.

구경의 위치를 찾아 저장하고 다음 단계로 넘어간다. 그 림 12는 order tracing 함수가 마스터 플랫에서 구경의 위 치를 찾아 그래프에 보여주는 모습이다.

(5) 파장 동정 : " calibration』

이전 단계가 끝나면 『calibration』 단추가 활성화 되고 이 단추를 누르면 ARC 프레임을 이용하여 파장을 동정한다. 그림 13 은 $\mathrm{ARC}$ 프레임의 각 구경에서 파장동정을 위 한 방출선을 찾아 개수를 그래프로 나타낸 것이다. 가로 축이 구경이고, 세로축은 해당 구경에서 동정된 방출선의 개수이다. $\mathrm{ARC}$ 가 여러 개일 경우 프로그램은 동정한 동 정된 방출선의 개수가 가장 많은 ARC 프레임으로 파장 정보를 결정한다.

(6) 천체 프레임 처리 : 『object』

활성화 된 『object』단추를 누르면 프로그램은 이전 단계 에서 구한 구경의 위치정보를 이용하여 천체 프레임을 
표 1. 각 처리 단계에서 자료처리 후 저장하는 파일

\begin{tabular}{lll}
\hline 단계 & \multicolumn{1}{c}{ mat 파일 } & \multicolumn{2}{c}{ 설명 } \\
\hline \multirow{2}{*}{ 전처리 } & BIAS.ma & 각각 마스터 바이어스와 마 \\
& FLAT.mat & 스터 플랫 \\
\hline 구경의 & \multirow{2}{*}{ Tracing.mat } & FLAT.mat에서 찾은 모든 구 \\
위치 결정 & 경의 위치정보가 든 파일 \\
\hline \multirow{3}{*}{ 파장 동정 Calibration.mat } & ARC 프레임에서 찾아서 파 동정된 방출선의 정보 \\
& & 가 든 파일 \\
\hline
\end{tabular}

1 차원으로 추출한다. 이후에 연속선 정규화를 하고 구경 별 파장 정보와 함께 모든 결과를 FITS 파일 형식에 맞추 어서 원 자료가 있던 폴더에 저장한다. 파일은 연속선 정 규화 전, 후의 자료가 모두 저장된다. 이를테면, 처리한 천체 프레임의 이름이 es12345.fits였다면 정규화 이전 자 료는 es12345.rx.fits로, 정규화가 된 자료는 ces12345.rx.fits로 저 장된다. 천체 프레임의 처리가 끝날 때마다 프로그램은 그래프에 $\mathrm{Ha}$ 가 있는 구경의 스펙트럼을 보여주어서 사 용자로 하여금 자료 처리 결과를 실시간 확인하도록 해 준다(그림 14).

모든 자료처리를 마치면 프로그램은 알람을 울려서 사용자에게 자료처리의 종료를 알린다.

(7) 순차적 자동 처리 : 『automatic』

최초에 프로그램을 시작하여서 단계 (2)에서 자료가 저장 된 폴더를 설정하면 위 단계 (3)의 『pre-precossing』단추 와 함께 『automatic』 단추도 함께 활성화 된다. 이 단추 를 누르면 단계 (3) 이후의 모든 처리 과정을 순차적으로 자동 실행하도록 하여 사용자의 편의를 도모하였다.

(8) 참고

프로그램은 각 단계에서 처리한 결과를 확장자가 .mat 인 파일로 저장한다(표 1).

$\mathrm{GRX}$ 는 각 자료처리 단계를 수행하기 이전에 해당 단 계의 결과 파일이 있는지 확인하고 이 파일이 있을 경우 해당 단계를 생략하고 이 파일을 그대로 사용 한다. 이를 테면 전처리 단계에서는 BIAS.mat나 FLAT.mat 파일이 있 으면 마스터 바이어스나 마스터 플랫을 만드는 과정을 생 략하고 이 자료를 그대로 사용한다. 이 확인 과정을 통해 서 자료처리 시간을 대폭 줄일 수 있다. 또 특별한 경우 가 아니라면 모든 바이어스 파일과 플랫 파일 대신 이 두 파일만을 저장하여 자료 저장 공간을 확보할 수 있다.
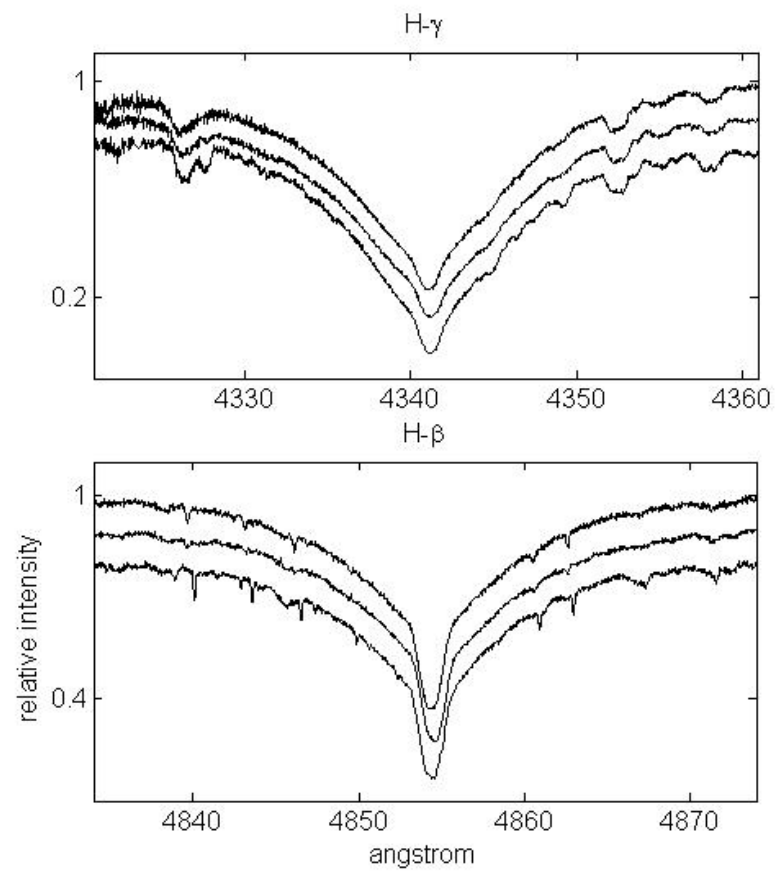

그림 15. $\ominus$ Aur의 $H_{\mathrm{\gamma}}$ 와 $H_{\beta}$ 스펙트럼. 위쪽 그래프가 $H_{\mathrm{\gamma}}$, 아래 그래프가 $H_{\beta}$ 이며, 각 그래프에서 제일 위 에 그려진 스펙트럼이 2004년 1월 15일, 중간이 2004년 2월 2일, 제일 아래가 2004년 11월 30일 관측 자료이다.

\section{Ap/Bp 형 자기별의 수소 발머선 프로파일 변화}

프로그램 $\mathrm{GRX}$ 는 기존의 자동화 프로그램 $\mathrm{RX}$ 의 모든 내 부 함수를 그대로 이식하고, 연속선 결정 알고리즘 IUS를 추가하여 관측으로 얻은 자료에 대해 전처리, 1 차원 스펙 트럼 추출, 파장동정, 연속선 결정의 전 과정을 GUI 환경 에서 수행할 수 있게 되었다. 이제 GRX를 이용한 천문학 적 연구의 사례로, 수소 흡수선이 보이는 미세 변동을 통 한 $\mathrm{Ap} / \mathrm{Bp}$ 형 자기별에 대한 연구 결과(Valyavin 외 2006)를 소개하고자 한다. 스펙트럼이 오랜 관측 기간 동안 미세 하게 변하는 정도를 확인하기 위해서는 연속선이 정밀하 게 결정되어야 한다. 따라서 이 결과는 GRX의 연속선 결 정 정밀도를 검증할 수 있는 수단이 될 수 있다. 뿐만 아 니라, 이러한 연구는 대량의 관측 자료를 통해 이루어지 므로 $\mathrm{GRX}$ 와 같은 자동화 프로그램의 사용이 필수적이다.

\section{1. 연구의 목적}

$\mathrm{Ap} / \mathrm{Bp}$ 형 자기별은 자기장 및 다른 역학적인 과정으로 인해 대류층에서 유도 전류가 발생한다. 이 유도 전류와 

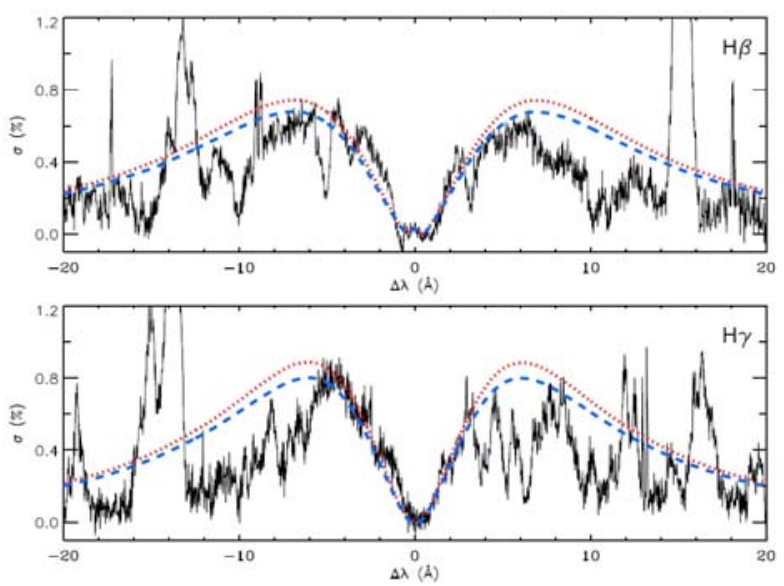

그림 16. 관측된 $\Theta$ Aur의 모든 스펙트럼으로부터 구한 $H_{\beta}, H_{\mathrm{\gamma}}$ 의 표준편차 스펙트럼. 실선이 표준편차 스펙 트럼이고, 이것을 쌍극 자기 별(dipolar magnetic star)과 사중극 자기 별(quadruple magnetic star)의 모델에 대해 맞춘 결과를 각각 점선과 쇄선으로 나타내었다.

자기장의 상호 작용으로 발생한 로렌츠 힘은 대기에 영향 을 미쳐 균질하지 않은 압력-온도 구조를 만든다. 이러한 상황에 있는 별이 회전을 하면 우리는 조금씩 다른 구조 를 가진 대기를 관측하게 되므로 이 때 보이는 흡수선의 형태도 별의 회전에 따라 달라진다(Stepien, 1978; Musielok \& Madej, 1981; Kroll, 1989; Valyavin et al., 2004). 이러한 이론적인 예측을 따라서 가장 밝은 $\mathrm{Ap} / \mathrm{Bp}$ 형 자기별을 관측하여 발머선이 보이는 체계적인 변동을 확인하고자 한다.

\section{2. 관측 및 자료처리}

보현산 천문대의 $1.8 \mathrm{~m}$ 망원경과 BOES를 이용하여 2004년 1월 10일부터 2005년 5월 30일까지 서로 다른 온도와 표 면 자기장을 가진 7 개 $\mathrm{Ap} / \mathrm{Bp}$ 형 자기별의 스펙트럼을 관 측하였다. 자료는 자기별의 회전에 따른 전체 주기 동안 0.05 주기 간격으로 획득하였고, GRX를 이용하여 모든 자 료를 처리하였다.

그림 15는 $\Theta \operatorname{Aur}\left(\mathrm{HD}\right.$ 40312)의 $H_{\mathrm{\gamma}}$ 와 $H_{\beta}$ 를 나타낸 것이다. 관측 자료는 총 43 프레임을 0.05 주기 간격으로 대 상 별의 한 회전 주기에서 고르게 얻었으므로 전체 스펙 트럼의 평균에 대한 표준편차 $(\sigma(\%))$ 는 흡수선이 별의 회전 주기 동안 보이는 변동의 지표로 삼을 수 있다. 이 결과 $\ominus$ Aur의 $H_{\beta}$ 와 $H_{\mathrm{\gamma}}$ 스펙트럼선의 윤곽으로부터 분 명하고 중요한 변동을 확인하였다.
표 2. 7 개 자기별에 대한 관측 결과

\begin{tabular}{llrrrr}
\hline \multicolumn{1}{c}{ 이름 } & SP & $\mathrm{T}_{\text {eff }}(\mathrm{K})$ & $\mathrm{B}_{\min }(\mathrm{G})$ & $\mathrm{B}_{\max }(\mathrm{G})$ & $\sigma_{\max }(\%)$ \\
\hline HD65339 & A2p & 8400 & $-5,400$ & +4200 & $<0.3$ \\
HD112413 & A0p & 11,500 & $-1,400$ & +1600 & $<1$ \\
HD112185 & Ap0 & 9,500 & -50 & +150 & $0.5-0.7 ?$ \\
HD196502 & Ap0 & 8,500 & -700 & 0 & $<0.7$ \\
HD19832 & B9p & 13,600 & -350 & +380 & $0.6 \pm 0.15$ \\
HD173650 & B9p & 10,600 & -500 & +700 & $0.5 \pm 0.2$ \\
HD40312 & B9p & 10,400 & -240 & +360 & $0.7 \pm 0.1$ \\
& & & & &
\end{tabular}

\section{3. 결과}

$\ominus$ Aur의 $H_{\beta}$ 와 $H_{\mathrm{\gamma}}$ 에서의 표준편차를 그림 16 에 나타 내었다. $H_{\beta}$ 와 $H_{\mathrm{\gamma}}$ 에서의 표준편차는 선의 날개(선의 중 심으로부터 $7 \AA$ 떨어진 부분, $\sigma_{\max }$ )에서는 증가하고 선 중 심에서는 감소하는 패턴을 보인다. 표준편차로 나타낸 이 러한 스펙트럼의 변동은 별에서의 non force-free magnetic field가 존재하는 것을 입증해 준다(Stepien, 1978; Kroll, 1989; Valyavin et al., 2004). 반면, 이 별 들의 다른 스펙트럼 영역에서는 표준 편차가 $0.1 \%$ 이하 임을 확인하였다. 이것은 $H_{\beta}$ 와 $H_{\mathrm{\gamma}}$ 에서의 스펙트럼 변 동이 의미 있는 물리적 현상임을 의미한다.

그리고 $56 \mathrm{Ari}$ 의 스펙트럼도 $\Theta \mathrm{Aur}$ 와 같은 표준편 차 패턴을 보여서 이 별에 대한 $\operatorname{Kroll}(1989)$ 의 결론을 확 인하였다. 그 외 다른 별들에서는 그다지 의미 있는 결과 를 확인할 수 없었다(표 2). 이 별들의 $H_{\beta}$ 스펙트럼 변 화의 상한값 $\left(\sigma_{\max }\right)$ 을 표에 나타내었다.

\section{5. 논의와 결론}

1 차 연구 (강동일 외 2005)에 이은 이번 연구로 BOES 데이터 자동처리 프로그램 개발을 완료하였다. 이번 연구 에서는 스펙트럼 연속선 결정 알고리즘 개발이 큰 부분으 로서, 이 연구에서 개발된 IUS 기법은 기존 알고리즘에 비하여 복잡한 스펙트럼의 정규화에 강점을 갖고 있는 것 으로 판단된다. 특히 기존 알고리즘에 비하여 구경의 양 끝단에서 정규화가 잘 되어서 각 구경을 이어 긴 스펙트 럼을 만들 때 겹치는 부분의 연속선이 잘 일치하였다. 프 로그램 측면에서는 GUI 기능을 대폭 강화하여 사용자가 쉽게 쓸 수 있도록 개선하였다. 본 연구에서 개발된 프로 그램 $\mathrm{GRX}$ 의 효율과 성능은 $\mathrm{Ap} / \mathrm{Bp}$ 형 자기별의 $H_{\beta}$ 와 
$H_{\mathrm{\gamma}}$ 스펙트럼선의 미세한 변화 연구에서 확인할 수 있었 다. 이 연구는 수동으로 처리하기에는 부담이 되는 많은 데이터가 이용되고, $H_{\beta}$ 와 $H_{\mathrm{y}}$ 같이 스펙트럼선이 넓어 서 수동으로 연속선을 결정하기에는 어려운 점이 있다. $\mathrm{GRX}$ 를 이용하여, $H_{\beta}$ 와 $H_{\mathrm{\gamma}}$ 스펙트럼의 미세한 변화를 $\mathrm{S} / \mathrm{N}$ 비 이내에서 감지할 수 있었다.

향후 과제로는 스펙트럼 추출에서 최적 추출 (optimal extraction) 기법을 도입하고, 우주선 제거 기능을 더 강화 하고, 연속선 결정 알고리즘에서도 방출선으로 인한 문제 에 보다 유연하게 대처하는 알고리즘을 개발하고자 한다. GRX를 이용해서 관측 자료로부터 천체의 스펙트럼을 추 출하는 자료처리의 전 과정이 어느 정도 완성되면, 이후 로는 스펙트럼에 대한 각종 연산 기능과 등가폭, 시선속 도, 천체의 화학조성비 등과 같은 물리량을 계산하는 각 종 함수를 개발하여 다양한 천문학적 결과를 도출 할 수 있는 프로그램으로 향상시키고자 한다.

\section{참고문헌}

강동일, 박홍서, 한인우, G. Valyavin, 이병철, 김강민, 2005, $\mathrm{BOES}$ 관측데이터의 자동처리 프로그램 개발, PKAS, 20: $97 \sim 107$

William P., Saul T., William V., \& Brian F., 2002, Numerical Recipes in $\mathrm{C}$

Bradley C., \& Dale O., 1996, An Introduction to Modern Astrophysics

Eduardo L. Martin, Rafael Rebolo \& Maria Rosa Zapatero-Osorio, 1996, AJ, 469:706-714

Stepien, K., 1978, A\&A, 70, 509

Musielok, B., \& Madej, J.C. 1981, ApJ, 244, 947

Kroll, R., 1989, Rev. Mex. Astron. Astrofis. 2, 194

Valyavin, G., Kochukhov, O., \& Piskunov, N., 2004, A\&A, 420, 993

Valyavin, G., Kochukhov, O., Shulyak, D., Lee, B.-C., Galazutdinov, G., Kim. K.-M., \& Han, Inwoo, 2005, JKAS, 38, 283

LaSala, J. \& Kurtz, M., 1984, ASP, 97, 605L

Luo, A. L., Zhao, Y.-H., 2001, Chinese Journal of Astronomy and Astrophysics, Vol. 1, No. 6, (2001) 563-572

Markova, N., 2002, A\&A, 385, 479-487 